\title{
Diagnosis of Presarcopenia Using Body Height and Arm Span for Postmenopausal Osteoporosis
}

This article was published in the following Dove Press journal:

Clinical Interventions in Aging

\section{Yuichi Ono \\ Naohisa Miyakoshi $\mathbb{C}$ \\ Yuji Kasukawa (D) \\ Manabu Akagawa (D) \\ Ryota Kimura \\ Itsuki Nagahata (D) \\ Yusuke Yuasa (1) \\ Chiaki Sato $\mathbb{D}$ \\ Yoichi Shimada}

Department of Orthopedic Surgery, Akita University Graduate School of Medicine, Akita, Japan
Correspondence: Yuichi Ono

Department of Orthopedic Surgery, Akita University Graduate School of Medicine,

I-I-I, Hondo, Akita-shi, Akita 0I0-8543, Japan

Tel $+8|-| 8-884-6 \mid 48$

Fax +8I-|8-836-26I7

Email yuichi.ono24@gmail.com
Purpose: Sarcopenia and osteoporosis are both serious health problems in postmenopausal women. The Asia Working Group for Sarcopenia recommends using the skeletal muscle index (SMI), which is height-adjusted appendicular skeletal muscle mass (ASMM). However, loss of height has been shown to be a common clinical finding in patients with osteoporosis. This study examined the prevalence of presarcopenia using height and arm span, which is a predictor of height, and investigated the diagnostic accuracy for presarcopenia.

Methods: A total of 55 post-menopausal osteoporotic patients aged 62-95 years underwent bioelectrical impedance analysis (BIA) for ASMM measurement and dual-energy X-ray absorptiometry (DXA) scan for bone mineral density (BMD). Anthropometric measurements, including height, weight, and arm span were taken, and body mass index (BMI), SMI, and arm span-adjusted SMI (Arm span SMI) were calculated. Presarcopenia was defined as SMI or Arm span SMI $<5.7 \mathrm{~kg} / \mathrm{m}^{2}$ in this study.

Results: The prevalence of presarcopenia was $27.3 \%$ and $38.2 \%$ evaluated by SMI and Arm span SMI, respectively. The prevalence of presarcopenia was higher when evaluated by Arm span SMI than by SMI. In the presarcopenia group diagnosed only by Arm span SMI ( $\mathrm{n}=11)$, the arm span-height difference was significantly higher $(p<0.001)$ and the percentage of young adult mean (YAM) femoral neck-BMD was significantly lower $(p=0.013)$ compared to the normal group diagnosed by both SMI and Arm span-SMI (n=29).

Conclusion: These results indicated that Arm span SMI might be useful for the diagnosis of sarcopenia in patients with severe osteoporosis and kyphosis.

Keywords: arm span, body height, osteoporosis, presarcopenia, skeletal muscle mass

\section{Introduction}

Sarcopenia is a syndrome characterized by progressive and generalized loss of skeletal muscle mass and strength with a risk of adverse outcomes such as physical disability, poor quality of life, and death. ${ }^{1}$ Since there are several common factors in osteoporosis and sarcopenia, such as aging, malnutrition, vitamin D deficiency, disuse, chronic inflammation, and decreased levels of sex steroid hormones, many studies of the association between osteoporosis and sarcopenia have been reported. $^{2,3}$ The Asia Working Group for Sarcopenia (AWGS) recommends using the skeletal muscle index (SMI), which is height-adjusted skeletal muscle mass, defined by appendicular skeletal muscle mass (ASMM) $/$ height $^{2}$ for muscle mass measurement in sarcopenia research. ${ }^{4}$ The European Working Group on Sarcopenia in Older People (EWGSOP) defined low muscle mass only as "presarcopenia". Although loss of height has been shown to be a common clinical finding 
accompanying vertebral fracture and kyphosis in elderly patients with osteoporosis, ${ }^{5}$ it is unclear whether heightadjusted skeletal muscle mass is accurate for evaluating sarcopenia in patients with osteoporosis.

On the other hand, arm span has been shown to be a predictor of peak height. ${ }^{6,7}$ Measurements of arm span are unaffected by height loss due to kyphosis and vertebral fractures. Arm span and height were consistent during ages of the $20 \mathrm{~s}$ to the $40 \mathrm{~s} .{ }^{8}$ Arm span did not change during aging, even though the height was shorter due to aging. However, there have been no studies examining skeletal muscle mass adjusted by arm span in elderly patients with osteoporosis.

Given this background, the aims of this study were to evaluate the prevalence of presarcopenia using height and arm span and to investigate the diagnostic accuracy for presarcopenia.

\section{Methods}

This observational, cross-sectional study was approved by the Ethical Review Board of Akita University Hospital (IRB approval no., 1974), and all patients provided written, informed consent as per the requirements of the Declaration of Helsinki.

This study included 55 post-menopausal osteoporotic patients aged over 62 years (range, 62-95 years) who had visited our outpatient clinics for the treatment of osteoporosis. The exclusion criteria were as follows: (1) patients with hemiplegia due to central nervous system or peripheral nerve disease; (2) patients who could not stand alone; and (3) patients who had significant range of motion restrictions of the shoulders or elbows. All subjects underwent both bioelectrical impedance analysis (BIA) (MC-780A-N, TANITA, Tokyo, Japan) for appendicular skeletal muscle mass (ASMM) and dual-energy X-ray absorptiometry (DXA) (QDR 4500A, Hologic, Waltham, MA, USA) measurements for bone mineral density (BMD) of the lumbar spine and femoral neck at our hospital. ASMM $[\mathrm{kg}] / \mathrm{arm} \operatorname{span}^{2}\left[\mathrm{~m}^{2}\right]$ was defined as Arm span SMI. SMI (ASMM $[\mathrm{kg}] /$ height $^{2}\left[\mathrm{~m}^{2}\right]$ ) and Arm span SMI were calculated.

Anthropometric measurements, including height and weight, were taken, and body mass index (BMI; weight $[\mathrm{kg}] /$ height $\left.^{2}\left[\mathrm{~m}^{2}\right]\right)$ was calculated.

Arm span was measured according to the previously reported methods. ${ }^{9,10}$ To obtain arm span measurements, each subject in the standing position was asked to raise her arms to a $90^{\circ}$ angle from the trunk and extend her arms horizontally. The distance between the tips of the middle fingers in unit increments of $0.1 \mathrm{~cm}$ was then measured.

Thoracic and lumbar spine $\mathrm{X}$-ray films in lateral views in the neutral/lateral decubitus position were taken with a filmtube distance of $1 \mathrm{~m}$; thoracic films were centered at $\mathrm{T} 8$, lumbar films at L3. ${ }^{11}$ Subsequently, all visualized vertebrae were evaluated for deformity using a semiquantitative visual scoring system. ${ }^{12}$ Using this system, Grade 1 and above were considered to be a vertebral fracture.

Wall-occiput distance (WOD) was used for simple kyphosis evaluation. Green et $\mathrm{al}^{13}$ reported that WOD could be used to screen for undiagnosed vertebral fractures. Each participant was asked to stand straight against a wall with her heels, buttocks, and back touching the wall. The horizontal distance between the wall and the back of the head was measured in increments of $5 \mathrm{~mm}$. When the value of WOD was $5 \mathrm{~mm}$ or more, it was defined as kyphosis.

The definition of presarcopenia was based on the proposals from AWGS and EWGSOP. ${ }^{1,4}$ The recommended cutoff values for low muscle mass were $5.7 \mathrm{~kg} / \mathrm{m}^{2}$ for women using BIA, defined by SMI. ${ }^{4}$ Following this, Arm span SMI $<5.7 \mathrm{~kg} / \mathrm{m}^{2}$ was also defined as presarcopenia in this study.

EZR software version 1.27 (Saitama Medical Center, Jichi Medical University, Saitama, Japan) ${ }^{14}$ was used for statistical analysis. Continuous variables are expressed as means \pm standard deviation. Differences between body height and arm span and between SMI and Arm span SMI were evaluated using paired $t$-tests. In the normal SMI group, the difference between the normal group and the presarcopenia group by Arm span SMI was evaluated using the Mann-Whitney $U$-test and Fisher's exact test. Values of $p<0.05$ were considered significant.

\section{Results}

In all cases, the arm span, average $149.0( \pm 6.6) \mathrm{cm}$, was significantly higher than the height, average $144.5( \pm$ 7.7) $\mathrm{cm}(\mathrm{p}<0.05)$. On the other hand, Arm span SMI, $5.88( \pm 0.96) \mathrm{kg} / \mathrm{m}^{2}$ was significantly lower than SMI, 6.24 $( \pm 0.85) \mathrm{kg} / \mathrm{m}^{2}(\mathrm{p}<0.05)$ (Table 1). The prevalence of presarcopenia was $27.3 \%$ and $38.2 \%$ evaluated by SMI and Arm span SMI, respectively. The prevalence of presarcopenia evaluated by Arm span SMI was higher than that evaluated by SMI, but the difference was not significant $(p=0.31)($ Table 2$)$.

In the normal group evaluated by SMI $(n=40), 29$ patients were diagnosed as normal and 11 patients were 
Table I Measured Values for the Study Patients with Osteoporosis

\begin{tabular}{|l|l|}
\hline Variable & $\mathbf{n = 5 5}$ \\
\hline Age $(\mathrm{y})$ & $80.5 \pm 7.5$ \\
Height $(\mathrm{cm})$ & $144.5 \pm 7.7$ \\
Arm span $(\mathrm{cm})$ & $149.0 \pm 6.6 *$ \\
Weight $(\mathrm{kg})$ & $48.5 \pm 8.9$ \\
BMI $\left(\mathrm{kg} / \mathrm{m}^{2}\right)$ & $23.3 \pm 3.8$ \\
ASMM $(\mathrm{kg})$ & $13.1 \pm 2.2$ \\
SMI $\left(\mathrm{kg} / \mathrm{m}^{2}\right)$ & $6.24 \pm 0.85 *$ \\
Arm span SMI $\left(\mathrm{kg} / \mathrm{m}^{2}\right)$ & $5.88 \pm 0.96$ \\
Lumbar spine-BMD $\left(\mathrm{g} / \mathrm{cm}^{2}\right)$ & $0.747 \pm 0.156$ \\
Percentage of YAM lumbar spine-BMD (\%) & $74.5 \pm 14.5$ \\
Total hip-BMD $\left(\mathrm{g} / \mathrm{cm}^{2}\right)$ & $0.572 \pm 0.092$ \\
Percentage of YAM total hip-BMD (\%) & $68.5 \pm 9.9$ \\
No. of patients with vertebral fracture (\%) & $24(43.6 \%)$ \\
No. of patients with kyphosis (\%) & $24(43.6 \%)$ \\
\hline
\end{tabular}

Notes: Values are the means \pm standard deviation. ${ }^{*} p<0.05$ vs. height or Arm span SMI, respectively, by the paired $t$-test.

Abbreviations: BMI, body mass index; ASMM, appendicular skeletal muscle mass; SMI, skeletal muscle index; BMD, bone mineral density; YAM, young adult mean.

Table 2 Prevalence of Presarcopenia Evaluated by SMI and Arm Span SMI

\begin{tabular}{|l|l|l|}
\hline & $\begin{array}{l}\text { Normal } \\
\text { n (\%) }\end{array}$ & $\begin{array}{l}\text { Presarcopenia } \\
\text { n (\%) }\end{array}$ \\
\hline SMI & $40(72.7 \%)$ & $15(27.3 \%)$ \\
Arm span SMI & $34(61.8 \%)$ & $21(38.2 \%)$ \\
\hline
\end{tabular}

Abbreviation: SMI, skeletal muscle index.

defined as presarcopenia using Arm span SMI. In the presarcopenia group diagnosed only by Arm span SMI $(\mathrm{n}=11)$, the arm span-height difference was significantly higher $(p<0.001)$, and the percentage of young adult mean (YAM) femoral neck-BMD was significantly lower $(p=0.013)$ compared to the normal group diagnosed by both SMI and Arm span-SMI $(\mathrm{n}=29)$. However, there were no significant differences between these two groups in age, arm span, height, weight, BMI, presence of vertebral body fracture, kyphosis, and lumbar spine BMD $(p>0.05)$ (Table 3).

\section{Discussion}

In this study, the prevalence of presarcopenia evaluated by Arm span SMI was higher than that by SMI, and subjects diagnosed as having presarcopenia by Arm span SMI, although they were normal by SMI, had a greater arm span-height difference, lower ASMM, and lower percentage of YAM femoral neck-
Table 3 Comparison of Variables Between the Normal and Presarcopenia Groups Evaluated by Arm Span SMI in the Normal SMI Group

\begin{tabular}{|c|c|c|c|}
\hline Arm Span SMI & $\begin{array}{l}\text { Normal } \\
(n=29)\end{array}$ & $\begin{array}{l}\text { Presarcopenia } \\
(n=I I)\end{array}$ & $p$ \\
\hline Age (y) & $79.6 \pm 7.8$ & $82.7 \pm 6.4$ & 0.235 \\
\hline Height $(\mathrm{cm})$ & $145.8 \pm 6.9$ & $|4| . \mid \pm 7.8$ & 0.070 \\
\hline Arm span $(\mathrm{cm})$ & $148.4 \pm 6.4$ & $152.5 \pm 5.6$ & 0.068 \\
\hline $\begin{array}{l}\text { Arm span-Height } \\
\text { difference }(\mathrm{cm})\end{array}$ & $2.6 \pm 6.0$ & $11.4 \pm 6.7$ & $<0.001$ \\
\hline Weight (kg) & $52.7 \pm 8.7$ & $47.8 \pm 6.9$ & 0.097 \\
\hline BMI $\left(\mathrm{kg} / \mathrm{m}^{2}\right)$ & $24.8 \pm 3.3$ & $24.1 \pm 3.6$ & 0.573 \\
\hline ASMM (kg) & $14.43 \pm 1.86$ & $12.28 \pm 0.99$ & $<0.001$ \\
\hline $\mathrm{SMI}\left(\mathrm{kg} / \mathrm{m}^{2}\right)$ & $6.78 \pm 0.66$ & $6.18 \pm 0.35$ & 0.007 \\
\hline Arm span SMI (kg/m²) & $6.55 \pm 0.67$ & $5.28 \pm 0.27$ & $<0.001$ \\
\hline Lumbar spine-BMD $\left(\mathrm{g} / \mathrm{cm}^{2}\right)$ & $0.774 \pm 0.152$ & $0.75 I \pm 0.188$ & 0.699 \\
\hline $\begin{array}{l}\text { Percentage of YAM lumbar } \\
\text { spine-BMD (\%) }\end{array}$ & $77.1 \pm 14.3$ & $74.9 \pm 16.1$ & 0.683 \\
\hline Femoral neck-BMD $\left(\mathrm{g} / \mathrm{cm}^{2}\right)$ & $0.601 \pm 0.097$ & $0.536 \pm 0.078$ & 0.054 \\
\hline $\begin{array}{l}\text { Percentage of YAM } \\
\text { femoral neck-BMD (\%) }\end{array}$ & $72.3 \pm 9.1$ & $63.9 \pm 9.1$ & 0.013 \\
\hline $\begin{array}{l}\text { No. of patients with } \\
\text { vertebral fracture (\%) }\end{array}$ & $12(4 \mid .4 \%)$ & 5 (45.5\%) & 1 \\
\hline $\begin{array}{l}\text { No. of patients with } \\
\text { kyphosis (\%) }\end{array}$ & 12 (4I.4\%) & $6(54.5 \%)$ & 0.498 \\
\hline
\end{tabular}

Note: Values are the means \pm standard deviation.

Abbreviations: BMI, body mass index; ASMM, appendicular skeletal muscle mass; SMI, skeletal muscle index; BMD, bone mineral density; YAM, young adult mean.

BMD compared to normal muscle mass subjects. The present results suggest that SMI overestimates muscle mass due to decreased height in patients with severe osteoporosis.

Since arm span tends to remain constant with advancing age, it was reported that using this parameter as a proxy for the peak height of an individual was useful. ${ }^{9,15}$ Additionally, it was reported that using arm span-height difference measurements during osteoporosis screening was an effective method of screening middle-aged and elderly women. ${ }^{10}$ Shimokata et al reported that the age-related SMI decrease of women was very small compared to men during the 12-year study period, but muscle quality decreased with aging. ${ }^{16}$ Arm span SMI might be useful as an indicator of the diagnosis of sarcopenia and for age-related muscle mass assessment of patients with osteoporosis. Thus, it is considered that arm span is an important physical measurement value for osteoporosis patients.

In the present study, the arm span-height difference was significantly higher in the presarcopenia group than in the 
normal group. However, there was no significant difference in the number of patients with vertebral fracture or kyphosis evaluated by WOD between the presarcopenia and normal groups. In addition to vertebral fractures, several factors, including muscle weakness, postural changes, intervertebral disc degeneration, and joint space narrowing, might be related to the height loss of elderly osteoporotic patients. ${ }^{17}$

There are several limitations in this study. First, the degree of kyphosis was not quantified, because spinopelvic parameters were not measured. Second, because the grip strength was not measured, a definitive diagnosis of sarcopenia could not be made. Third, the accuracy of the cutoff value for presarcopenia using arm span-adjusted SMI is uncertain. More validation studies of the arm-span cutoff value are needed to substantiate the clinical utility of arm span-SMI. Future studies should measure muscle strength and arm span, and focus on the association with sarcopenia.

In conclusion, this study examined the diagnostic accuracy of presarcopenia using height-adjusted skeletal muscle mass and arm span-adjusted skeletal muscle mass in women with osteoporosis. The prevalence of presarcopenia was higher using Arm span SMI than using SMI. It was suggested that Arm span SMI might be useful for the diagnosis of sarcopenia in patients with severe osteoporosis and kyphosis.

\section{Author Contributions}

All authors contributed to data analysis, drafting or revising the article, gave final approval of the version to be published, and agree to be accountable for all aspects of the work.

\section{Disclosure}

The authors report no conflicts of interest in this work.

\section{References}

1. Cruz-Jentoft AJ, Baeyens JP, Bauer JM, et al. Sarcopenia: European consensus on definition and diagnosis: report of the European Working Group on sarcopenia in older people. Age Ageing. 2010;39 (4):412-423. doi:10.1093/ageing/afq034

2. Miyakoshi N, Hongo M, Mizutani Y, Shimada Y. Prevalence of sarcopenia in Japanese women with osteopenia and osteoporosis. $J$ Bone Miner Metab. 2013;31(5):556-561. doi:10.1007/s00774-013-0443-z
3. Hida $\mathrm{T}$, Ishiguro $\mathrm{N}$, Shimokata $\mathrm{H}$, et al. High prevalence of sarcopenia and reduced leg muscle mass in Japanese patients immediately after a hip fracture. Geriatr Gerontol Int. 2013;13(2):413-420. doi:10.1111/ggi.2013.13.issue-2

4. Chen LK, Liu LK, Woo J, et al. Sarcopenia in Asia: consensus report of the asian working group for sarcopenia. J Am Med Dir Assoc. 2014;15(2):95-101. doi:10.1016/j.jamda.2013.11.025

5. Briot K, Legrand E, Pouchain D, Monnier S, Roux C. Accuracy of patient-reported height loss and risk factors for height loss among postmenopausal women. CMAJ. 2010;182(6):558-562. doi:10.1503/ cmaj.090710

6. Mohanty SP, Babu SS, Nair NS. The use of arm span as a predictor of height: a study of South Indian women. J Orthop Surg (Hong Kong). 2001;9(1):19-23. doi:10.1177/230949900100900105

7. Jarzem PF, Gledhill RB. Predicting height from arm measurements. J Pediatr Orthop. 1993;13(6):761-765. doi:10.1097/01241398199311000-00014

8. Quanjer PH, Capderou A, Mazicioglu MM, et al. All-age relationship between arm span and height in different ethnic groups. Eur Respir J. 2014;44(4):905-912. doi:10.1183/09031936.00054014

9. Wang XF, Duan Y, Henry M, Kim BT, Seeman E. Body segment lengths and arm span in healthy men and women and patients with vertebral fractures. Osteoporos Int. 2004;15(1):43-48. doi:10.1007/ s00198-003-1496-y

10. Abe K, Tamaki J, Kadowaki E, et al. Use of anthropometric indicators in screening for undiagnosed vertebral fractures: a cross-sectional analysis of the Fukui Osteoporosis Cohort (FOC) study. BMC Musculoskelet Disord. 2008;9:157. doi:10.1186/14712474-9-157

11. Miyakoshi N, Itoi E, Murai H, Wakabayashi I, Ito H, Minato T. Inverse relation between osteoporosis and spondylosis in postmenopausal women as evaluated by bone mineral density and semiquantitative scoring of spinal degeneration. Spine (Phila Pa 1976). 2003;28 (5):492-495. doi:10.1097/01.BRS.0000048650.39042.58

12. Genant HK, Wu CY, van Kuijk C, Nevitt MC. Vertebral fracture assessment using a semiquantitative technique. J Bone Miner Res. 1993;8(9):1137-1148. doi:10.1002/jbmr.5650080915

13. Green AD, Colon-Emeric CS, Bastian L, Drake MT, Lyles KW. Does this woman have osteoporosis? JAMA. 2004;292(23):2890-2900. doi:10.1001/jama.292.23.2890

14. Kanda Y. Investigation of the freely available easy-to-use software 'EZR' for medical statistics. Bone Marrow Transplant. 2013;48 (3):452-458. doi:10.1038/bmt.2012.244

15. van Leer EM, van Noord PA, Seidell JC. Components of adult height and height loss. Secular trend and effects of aging in women in the DOM project. Ann Epidemiol. 1992;2(5):611-615. doi:10.1016/10472797(92)90005-B

16. Shimokata H, Ando F, Yuki A, Otsuka R. Age-related changes in skeletal muscle mass among community-dwelling Japanese: a 12-year longitudinal study. Geriatr Gerontol Int. 2014;14(Suppl 1):85-92. doi:10.1111/ggi.12219

17. Hannan MT, Broe KE, Cupples LA, Dufour AB, Rockwell M, Kiel DP. Height loss predicts subsequent hip fracture in men and women of the Framingham Study. J Bone Miner Res. 2012;27 (1):146-152. doi:10.1002/jbmr.557 


\section{Publish your work in this journal}

Clinical Interventions in Aging is an international, peer-reviewed journal focusing on evidence-based reports on the value or lack thereof of treatments intended to prevent or delay the onset of maladaptive correlates of aging in human beings. This journal is indexed on PubMed Central, MedLine, CAS, Scopus and the Elsevie
Bibliographic databases. The manuscript management system is completely online and includes a very quick and fair peer-review system, which is all easy to use. Visit http://www.dovepress.com/ testimonials.php to read real quotes from published authors. 